\title{
A New Evaluation Technique Through Serious Games for Children with ASD
}

\author{
https://doi.org/10.3991/ijet.v15i11.12843
}

\author{
Tahiri Najoua ${ }^{(凶)}$, El Alami Mohamed \\ Abdelmalek Essaadi University, Tétouan, Morocco \\ najoua.tahiriegmail.com
}

\begin{abstract}
Assessment at preschool age plays a crucial role in the process of learning especially for children with autism spectrum disorder (ASD), whom encounter communication difficulties as exchanging thoughts or information by speech, writing or nonverbal expression. Therefore, a well-designed assessment method is necessary in order to guide learning and serve as a powerful tool to reinforce children's motivation to learn. Information about what a child with ASD knows, understands and is able to do is used by tutors to adjust their teaching strategies. All assessment methods have different purposes before, during or after instruction. Besides, formative assessment is the most recommended type that helps improving children's learning and it takes place during the learning process. Also, serious games provide a context for assessing a broader range of skills and constructs compared to traditional assessment approaches. In this article, we propose a new technique for evaluating the degree of concept's assimilation of children with ASD through serious games. It allows identifying concepts that children are struggling to understand and skills they are having difficulty acquiring.
\end{abstract}

Keywords - Evaluation, ASD, Serious Games, Education, Technique

\section{Introduction}

Autism Spectrum Disorder (ASD) is a complex disorder characterized by social and communication difficulties and by restricted or repetitive behaviors or interests [1]. These difficulties considerably affect the skills necessary for learning, which disrupts the acquisition, understanding, use and processing of verbal or non-verbal information.

It is not only about the acquisition of basic skills such as reading, writing and / or mathematics, but even higher skills such as organization, time planning, abstract reasoning, long-term memory or short term and attention.

Children with ASD have trouble interpreting social cues which influence their ability to adapt their behaviors or even exhibit inappropriate social behaviors due to abnormal social development. It is an evolutionary process by which individuals adapt their learning skills and behavior to the context [2].

Assessment is a process that involves gathering, analyzing and interpreting learning information in order to make a judgment on the child's situation and to make a decision on his or her further development. Assessment generally has two functions, a social and 
an educational function. The forms of evaluation are classified into several categories according to the assigned function (summative, formative and certification, etc.) [3-4]. The National Foundation for Educational Research in the United Kingdom [5] classifies the types of assessment according to the learning objective, it distinguishes three classes:

- Assessment for learning

- Assessment as learning

- Assessment of learning

In addition, Roediger [6] defines evaluation as "a task of mobilizing and using knowledge, so it has the effect of reinforcing learning". To evaluate [7] is to situate an act in relation to a reference. However, evaluation as a measuring instrument consists in assigning a value to this difference between act and reference. It is also an essential tool for the design, implementation and regulation of a teaching-learning situation. However, children with ASD struggle in self-expression, so assessing what a child with ASD has learned seems to be a complicated issue. Micah Mazurek [8] assumes that young people with ASD are attracted to video games because they can be rewarded without having to first socialize or communicate. Therefore, using the potential of serious games in such situations provides acquiring implicitly their understanding.

This article presents a new evaluation technique that allows assessing an autistic child's understanding through serious games. In this perspective, the article first presents related work to the evaluation topic; it establishes the importance of evaluation in the learning process. Then, it sets out the potential of serious game as an assessment tool especially for children with ASD. Subsequently, the second part is devoted to the proposed technique. The fourth section exhibits a practical example of the proposed technique. Finally, it presents a discussion of the strengths and limitations of the proposed technique.

\section{$2 \quad$ Literature Review}

Evaluation is an integral part of the learning process. Traditionally, assessment of learning has focused only on factual content, and progress has been assessed using methods such as written exams. However, in order to assess learning in areas such as creativity and critical thinking, it is necessary to use non-traditional methods. Increasingly, tutors will use strategies such as observation, interview, written and oral work and performance evaluation to gather knowledge in order to measure the child's progress.

Hence, the immersive nature of SGs allows children to make decisions in a context, or even find themselves in the shoes of a character. As the game progresses, the child learns to fit to these needs and practices in different types of situations.

The term Serious Games was outlined in the founding work of Clark Abt [9]. He defines it as follows: "these games have an explicit and carefully designed educational purpose and are not intended to be primarily played for fun". 
Serious games are an increasingly interwoven practice in several fields and are designed for various purposes, such as: entertainment, learning, therapy or social control [10]. When playing, the child expresses himself indirectly through his choices, his reactions and his decisions: "Play is the highest development of childhood, because it alone is the free expression of what is in his soul. ... Children's play is not a simple sport. It is full of meaning and import" [11].

Several studies have proved the efficiency of using Serious Games as a tool to encourage the development of communication, learning process and social behavior of people with ASD, in addition to traditional therapeutic approaches. From Urturi et al. [12] have implemented an Android application to educate first aid for people with ASD and have proven that people with autism feel more relaxed by practicing the activities as educational games. Bernardes et al. [13] published a study on an SG aimed at training people with ASD to use the bus, the publication demonstrates the power of games and virtual reality in improving the capacities of people with ASD. ISpectrum [14] is another serious software developed in the training field. It aims to enhance work capacities and skills.

In this respect, the ludo-pedagogy not only promotes active learning as described by Matsushita [15], but also the evaluation procedure. Through SGs, tutors could effectively measure the comprehension level of children with ASD in order to guide the content of the educational scenario.

El Alami et al. [16 - 17] argue that the precise determination of student learning has always been an important point for several objectives, such as the choice of corrective tactics to fix learning errors and improve the effectiveness of learning systems. Roediger and Karpicke [18] argue that assessment is a powerful means to improve learning. Indeed, monitoring autistic children's learning and obtaining regular feedback is a beneficial practice. Thus, the major advantage of the proposed technique is to provide early and targeted learning aids.

Most research work on evaluating children with ASD concern diagnostic. They differ according to the age and pathology of the target population, and are generally based on questionnaires, direct observation or interviews [19-24]. For instance, Millar et al. [25] present a serious game serving as a screening tool intended for children of school age, its objective is to diagnose if the child has an ASD or another neurodevelopmental disorder.

In addition, some projects are intended for families of children with ASD [26], health care providers [27], or tutors [28] in order to allow their awareness and attitudes towards ASD for but sensitization. Nevertheless, no project concerns using serious games as an evaluation tool in order to monitor the progress of the autistic children's learning.

The proposed technique allows to measure the children's action in a virtual context. It requires a fast analysis of sensorimotor information in order to reveal hidden states, including mental states (such as beliefs, intentions). These games are designed in accordance with the axes of KASP methodology [29] which ensures better modeling of the game scenes taking into account the cognitive, emotional and sensory aspects of the child. Based on child's knowledge models, derived from DIAUTIS platform [30], it allows an adapted game scene suitable to each children's needs. DIAUTIS offers a battery of tests of different categories, it aims to identify the category of autism spectrum 
disorder as well as its intensity through the ability to learn from experience. It is a multiagent system with the functionality of cognitive, fuzzy and affective computing.

\section{Proposed Technique}

Assessment plays an essential role in providing useful information to guide learning and to adapt the learning mode to autistic children's specificities. The main goal of the technique is to measure the degree of assimilation of a concept by a child with ASD in order to be able to assess his learning progress, this evaluation will allow children, tutors and parents, as well as educational community at large, to be informed about learning outcomes in order to highlight successes, plan interventions and continue to promote learning.

Evaluating an autistic child's understanding in relation to his environment is a complex practice. For this reason, the authors propose to use serious games as an intermediary to take advantage of the motivation and commitment of children in order to measure the degree of assimilation of the concepts exposed in scenes of the game.

A game is characterized by an intention, a genre, a main concept, conditions of victory and defeat which are the objectives of the scenes composing the game, and a narration. The harmony between the objective and the concepts making up the scenes must first ensure the effectiveness of the scenario in order to recount a coherent and interesting story.

In order to measure the degree of assimilation of a concept by a child with ASD, it is necessary to take into account the sub-concepts constructing the main concept (objective of the game). Mathematically, it is referred to compare the sub-concept's weights of the child to those of the expert in order to identify actions that caused a significant degradation of the sub-concepts' weights. The actions made by the child influence the weights of the sub-concepts which generates a new vector consisting of new values of the sub-concept's weights.

Therefore, the expert is led to propose a serious game allowing the evaluation of a concept in children with ASD. This game is made up of several scenes:

$$
\text { Game }=\left\{S_{\alpha} ; S_{\beta} ; S_{\gamma} ; \cdots\right\} \text { such that } S_{i} \text { :a game scene }
$$

The main objective of the game is identical to the main concept that the expert intends to evaluate. Each game scene is formed of several objects, where each object represents a sub-concept. The objects interact with each other following the actions made by the child:

$$
\begin{aligned}
& S_{\gamma} \\
& =\left(C_{\gamma}, A_{\gamma}\right) \text { such that }\left\{\begin{array}{l}
C_{\gamma}=\left\{C_{\gamma_{1}} ; C_{\gamma_{2}} ; C_{\gamma_{3}} ; \cdots\right\}: \text { set of the scene's concepts } S_{\gamma} \\
A_{\gamma}=\left\{A_{\gamma_{1}} ; A_{\gamma \alpha_{2}} ; A_{\gamma_{3}} ; \cdots\right\}: \text { set of the scene's actions } S_{\gamma}
\end{array}\right.
\end{aligned}
$$

Any action is characterized by a weight, which expresses the influence of the action on the concept. This weight is expressed using the Likert scale [31], which is considered 
one of the most reliable tools for measuring perceptions. It is made up of 5 levels (see Table 1):

$$
\forall A_{\gamma_{i}} \Rightarrow W_{\gamma_{i}} \in[1,5]
$$

Table 1. Likert scale

\begin{tabular}{|c|c|c|c|c|}
\hline $\mathbf{1}$ & $\mathbf{2}$ & $\mathbf{3}$ & $\mathbf{4}$ & $\mathbf{5}$ \\
\hline Very wrong action & Wrong action & Acceptable action & Correct action & Very correct action \\
\hline
\end{tabular}

In addition, any action is defined by:

- A triggering event: When an event is received, a transition can be triggered and switch the object to a new state assessment as learning

- Intensity: It is a weight that reflects the strength of the emitted action and it is specified by the expert.

- And a guard condition: It is evaluated only when the triggering event occurs. If the expression is false, the transition does not trigger, if it is true, the transition triggers and its effects occur.

Moreover, the expert assigns a weight to each concept to describe its importance in relation to the main concept (see Table 2). The weighting varies from scene to scene:

$$
\forall C_{\gamma_{i}} \Rightarrow V_{\gamma_{i}} \in[1,5]
$$

Table 2. Expert's weights of concepts

\begin{tabular}{|l|l|l|l|l|l|}
\hline \multicolumn{7}{|c|}{ Scene $: \boldsymbol{S}_{\gamma}$} \\
\hline Concepts & $\boldsymbol{C}_{\gamma_{1}}$ & $\boldsymbol{C}_{\gamma_{2}}$ & $\boldsymbol{C}_{\gamma_{3}}$ & $\boldsymbol{C}_{\gamma_{4}}$ & \\
\hline Weights/Main concept & $V_{\gamma_{1}}$ & $V_{\gamma_{2}}$ & $V_{\gamma_{3}}$ & $V_{\gamma_{4}}$ & \\
\hline
\end{tabular}

The expert first provides a semantic network of the scene (see Fig. 1). It is a model that gathers all the concepts and actions as well as their weights. Each concept is represented by a node, the oriented arc connecting two nodes expresses the influence of the action on the concept of destination. For each concept, the expert must specify at least five actions which reflect the weights on the scale[1,5]. The game scenes are specially designed to assess the autistic child's understanding using the KASP methodology [29]. It is a methodology for designing intelligent games centered on diagnosis, it takes into account the cognitive, emotional and sensory aspects of the child.

After a play session, a semantic sub-network of the child is generated (see Fig. 2). It inherits from the expert's semantic network and only contains the actions made by the child and associated concepts. 


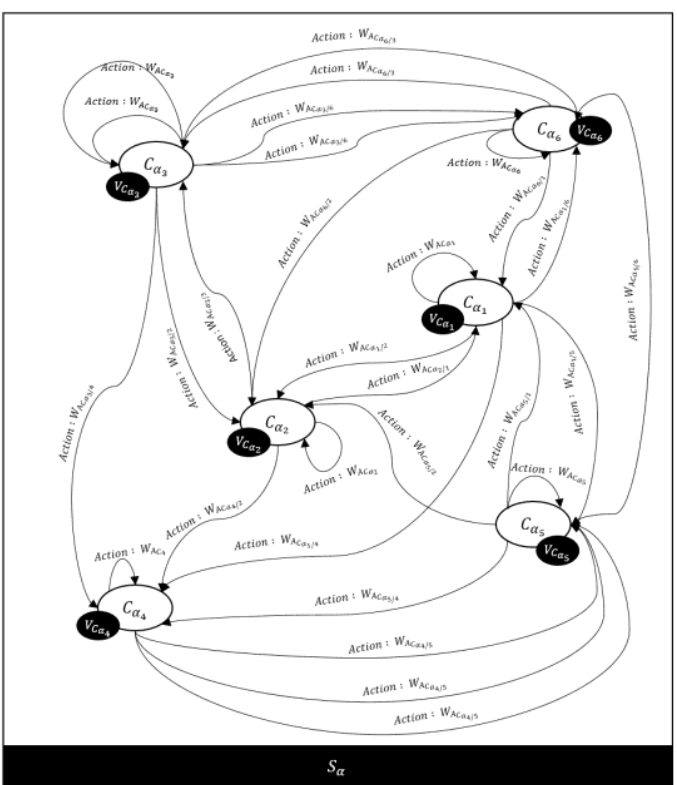

Fig. 1. Expert's semantic network of scene $S_{\alpha}$

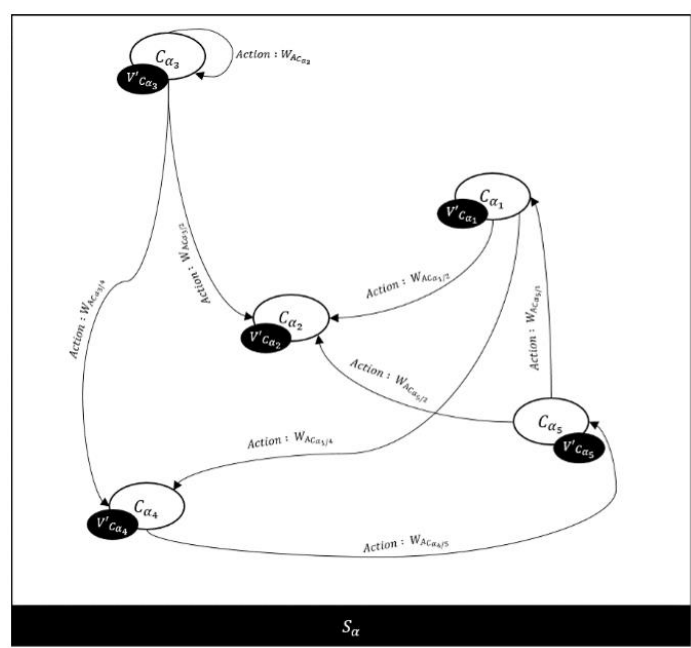

Fig. 2. Child's semantic network of scene $S_{\alpha}$

Thereafter, we generate two matrices from the semantic network, the first matrice matches to the expert (see Fig. 3) and the second is the child's matrice (see Fig. 4). Each matrice consists of $\mathrm{n}$ rows and $\mathrm{m}$ columns, the columns correspond to the concepts forming the scene and the rows to the actions, the value of the intersection row $x$ column is the weight of the action. Hence, the expert's matrice contains all the varieties of 
actions as well as all the concepts, and the one of the children is a sub-matrice of the expert.

\begin{tabular}{|c|c|c|c|c|c|c|}
\hline & $c_{\alpha_{1}}$ & $c_{\alpha_{2}}$ & $c_{\alpha_{3}}$ & $c_{\alpha_{4}}$ & $c_{\alpha_{5}}$ & $c_{\alpha_{6}}$ \\
\hline Action & $W_{A c_{\alpha_{1}}}$ & $W_{A_{c_{a_{2}}}}$ & $W_{A c_{c_{3}}}$ & $W_{A c_{c_{4}}}$ & $W_{A_{c_{\alpha_{5}}}}$ & $W_{A c_{\alpha_{\alpha_{b}}}}$ \\
\hline Action & 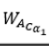 & $W_{A_{c_{\alpha_{2}}}}$ & $W_{A_{c_{c_{3}}}}$ & $W_{A_{c_{c_{4}}}}$ & $W_{A_{C_{C_{\alpha_{5}}}}}$ & 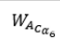 \\
\hline Action & $W_{A_{c_{\alpha_{1}}}}$ & $W_{A_{c_{\alpha_{z}}}}$ & $W_{A c_{c_{3}}}$ & $W_{A_{c_{c_{4}}}}$ & $W_{A_{C a_{5}}}$ & $W_{A_{c \alpha_{\alpha_{0}}}}$ \\
\hline Action & $W_{A_{c_{\alpha_{1}}}}$ & 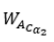 & $W_{A_{c_{c_{3}}}}$ & $W_{A_{c_{c_{4}}}}$ & $W_{A a_{a_{5}}}$ & $W_{A c_{\alpha_{\alpha_{b}}}}$ \\
\hline Action & $W_{A c_{\alpha_{\alpha_{1}}}}$ & $W_{A c_{a_{2}}}$ & $W_{A c_{c_{3}}}$ & $W_{A c_{a_{4}}}$ & $W_{A a_{a_{5}}}$ & $W_{A c_{\alpha_{\alpha_{b}}}}$ \\
\hline$\ldots$ & $\ldots$ & ... & ... & ... & ... & ... \\
\hline Action & $W_{A_{A_{\alpha_{1}}}}$ & 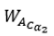 & $W_{A_{A_{c_{3}}}}$ & $W_{A_{A_{a_{4}}}}$ & $W_{A_{c_{c_{5}}}}$ & 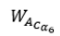 \\
\hline Action & $W_{A c_{\alpha_{\alpha_{1}}}}$ & $W_{A A_{\alpha_{2}}}$ & $W_{A C_{C_{2}}}$ & $W_{A C_{a_{A}}}$ & $W_{A c_{c_{55}}}$ & $W_{A c_{\alpha_{\alpha_{b}}}}$ \\
\hline
\end{tabular}

Fig. 3. Expert's matrice of scene $\mathrm{S} \alpha$

\begin{tabular}{|c|c|c|c|c|c|}
\hline & $C_{\alpha_{1}}$ & $C_{\alpha_{2}}$ & $C_{\alpha_{3}}$ & $C_{\alpha_{4}}$ & $C_{\alpha_{5}}$ \\
\hline Action & $W_{A c_{\alpha_{1}}}$ & 0 & 0 & 0 & 0 \\
\hline Action & 0 & $W_{A c_{\alpha_{2}}}$ & 0 & 0 & 0 \\
\hline Action & 0 & $W_{A c_{\alpha_{2}}}$ & 0 & 0 & 0 \\
\hline Action & 0 & $W_{A c_{\alpha_{2}}}$ & 0 & 0 & 0 \\
\hline Action & 0 & 0 & $W_{A c_{\alpha_{3}}}$ & 0 & 0 \\
\hline Action & 0 & 0 & 0 & $W_{A c_{\alpha_{4}}}$ & 0 \\
\hline Action & 0 & 0 & 0 & $W_{A c_{\alpha_{4}}}$ & 0 \\
\hline Action & 0 & 0 & 0 & 0 & $W_{A c_{\alpha_{5}}}$ \\
\hline
\end{tabular}

Fig. 4. Child's matrice of scene $\mathrm{S} \alpha$

Any action applied to a concept entails an influence on the weighting of the concept compared to the main concept $V_{\gamma_{i}}$.In order to calculate this new weighting, we perform a normalization of the Likert scale by transforming the weights [1,5] into values between $[0,1]$ as shown in Table 3 below:

Table 3. Normalized scale

\begin{tabular}{|c|c|c|c|c|}
\hline $\mathbf{1}$ & $\mathbf{2}$ & $\mathbf{3}$ & $\mathbf{4}$ & $\mathbf{5}$ \\
\hline 0,2 & 0,4 & 0,6 & 0,8 & 1 \\
\hline
\end{tabular}

A new weighting $V^{\prime} \gamma_{i}$ is calculated by applying the following formula (*): 


$$
\boldsymbol{V}^{\prime}{ }_{\alpha_{i}}=\boldsymbol{W}_{\alpha_{j}} \times \boldsymbol{W}_{\alpha_{k}} \times \boldsymbol{W}_{\alpha_{l}} \times \ldots \times \boldsymbol{V}_{\alpha_{i}}=\prod_{j=1}^{n} \boldsymbol{W}_{\alpha_{j}} \times \boldsymbol{V}_{\alpha_{i}} \quad \text { such that } n
$$

: the number of actions

At the end of each played scene, a new weighting of the concepts is calculated to measure the child's understanding of a specific concept through the decisions taken while playing. The interpretation of the result vector explains the way how the child perceives the main concept. Table 4 presents the new weights of concepts related to the main concept:

Table 4. Child's weights of concepts

\begin{tabular}{|l|c|c|c|c|c|}
\hline \multicolumn{7}{|c|}{ Scene $: \boldsymbol{S}_{\boldsymbol{\alpha}}$} \\
\hline Concepts & $\boldsymbol{C}_{\boldsymbol{\alpha}_{1}}$ & $\boldsymbol{C}_{\boldsymbol{\alpha}_{2}}$ & $\boldsymbol{C}_{\boldsymbol{\alpha}_{3}}$ & $\boldsymbol{C}_{\boldsymbol{\alpha}_{4}}$ & $\boldsymbol{C}_{\boldsymbol{\alpha}_{5}}$ \\
\hline Weights/Main concept & $\boldsymbol{V}_{\boldsymbol{\alpha}_{1}}$ & $\boldsymbol{V}_{\boldsymbol{\alpha}_{2}}$ & $\boldsymbol{V}_{\boldsymbol{\alpha}_{3}}$ & $\boldsymbol{V}_{\boldsymbol{\alpha}_{4}}$ & $\boldsymbol{V}_{\alpha_{5}}$ \\
\hline
\end{tabular}

Table 4 presents the child's vector of the weights of the concepts, which will be compared with the vector of the expert. Although, the expert's vector requires a preprocessing step before comparison for reducing its dimensionality in order to examine only the sub-concepts that appear in the child's matrice. Thus, we suggest the cosine similarity technique as a comparison tool to determine the degree of similarity between the assimilation of the main concept between the child and the expert. The cosine similarity is used to calculate the similarity between two n-dimensional vectors by determining the angle between them. This metric is often used in text mining. The cosine similarity formula is as follows:

$$
\text { Cosine similarity }=\frac{\sum_{i=1}^{n} x_{i} y_{i}}{\sqrt{\sum_{i=1}^{n} x_{i}^{2}} \sqrt{\sum_{i=1}^{n} y_{i}^{2}}}
$$

Figure 5 shows the angle indicating the degree of similarity between $\mathrm{x}$ and $\mathrm{y}$ where $\mathrm{x}$ and $\mathrm{y}$ are the vectors representing the expert and child vectors respectively of scene $S_{\alpha}$ :

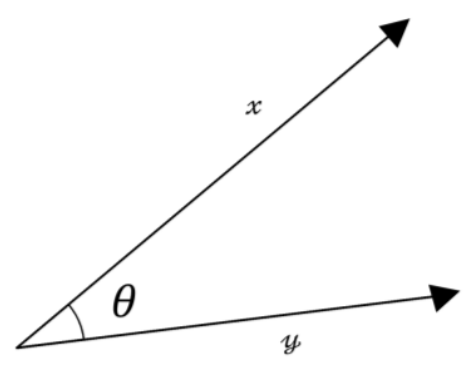

Fig. 5. Angle between vectors $x$ and $y$ 
Taking into account the obtained result, if the angle between the vector representing the weights of the sub-concepts compared to the main concept of the child and expert is acute, the higher is the understanding of the child. Unlike, if the angle is obtuse, so the main concept is not clear to the child.

Representing the measure of a concept's assimilation by a child with ASD allows the expert to better analyze how the child perceives this concept in reality. In addition, we propose to identify the actions that have caused a significant degradation of the weights of the sub-concepts. So, for each scene, we select the actions whose weight $W_{A_{c_{\alpha_{i}}}} \leq 3$, knowing that:

- if $\boldsymbol{W}_{\boldsymbol{A}_{\boldsymbol{C}_{\boldsymbol{\alpha}_{\boldsymbol{i}}}}} \leq \mathbf{3}$, a significant degradation is applied to the sub-concept

- if $\mathbf{4} \leq \boldsymbol{W}_{\boldsymbol{A}_{\boldsymbol{C}_{\boldsymbol{\alpha}_{\boldsymbol{i}}}}}<\mathbf{5}$, a weak degradation is applied to the sub-concept

- if $\boldsymbol{W}_{A_{\boldsymbol{c}_{\alpha_{i}}}}=\mathbf{5}$, the weighting of the sub-concept does not undergo any modification

Identifying these actions will allow the expert to identify for each child the concepts that are difficult to grasp. Subsequently, the tutors should be able to adapt the learning programs, emphasizing the shortcomings revealed by the proposed technique in order to reinforce the comprehension of the child with ASD.

\section{Case Study}

In this part, the authors propose a case study to measure the degree of a concept's assimilation of a child with ASD using the proposed technique, the concept is "getting ready to school". The game locates the child in various situations, where he is led to interact with objects in various pieces of house in order to get ready for school. The type of the game is "simulation", presenting an environment similar to reality. The game's semantic network is developed by the expert, and it contains all the scenes forming the game, as well as the concepts and actions defined for each scene. From this model, we deduce the expert's matrice, as well as the concept weighting vector regarding to the main concept (Table 5).

Table 5. Expert's weights of concepts

\begin{tabular}{|c|c|c|c|c|c|c|c|c|c|c|c|c|c|c|c|c|c|c|}
\hline Scene & \multicolumn{10}{|c|}{ Scene $: S_{\alpha}$} & \multicolumn{8}{|c|}{ Scene : $S_{\beta}$} \\
\hline 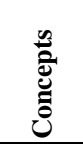 & 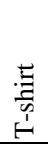 & 点 & 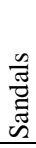 & 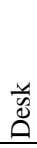 & $\begin{array}{l}\ddot{0} \\
\dot{0}\end{array}$ & 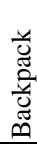 & $\begin{array}{l}\ddot{D} \\
0\end{array}$ & $\frac{z}{0}$ & $\begin{array}{l}\bar{\Xi} \\
\text { 气्ञ } \\
\text { 吾 }\end{array}$ & $\begin{array}{l}0 \\
0 \\
0 \\
0 \\
0 \\
3 \\
3 \\
3\end{array}$ & 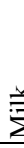 & 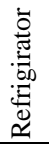 & 负 & $\begin{array}{l}\overline{3} \\
0 \\
0\end{array}$ & $\begin{array}{l}\bar{v} \\
\bar{d} \\
\dot{0}\end{array}$ & Е & $\frac{\bar{\partial}}{\bar{\partial}}$ & $\begin{array}{l}\frac{n}{\tilde{J}} \\
\stackrel{\tilde{U}}{\tilde{U}}\end{array}$ \\
\hline 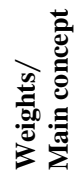 & 4 & 3 & 3 & 2 & 5 & 5 & 2 & 1 & 1 & 2 & 3 & 2 & 4 & 2 & 1 & 4 & 3 & 5 \\
\hline
\end{tabular}


This game allows the expert to evaluate the skills of the daily routine by simulating the real world through game scenes, a character is able to move from one piece to another and act on objects appearing in the scenes of the game. The goal is to measure the degree of assimilation of the child about his environment, his habits and his behaviors. Figure 7 illustrates two game scenes: the kitchen and the bedroom. Among the objectives of the scene happening in the kitchen, the child is led to prepare his breakfast. The objective is to evaluate if the child is able to position some tools in their correct location, also if the child differentiates between furniture and food, etc.

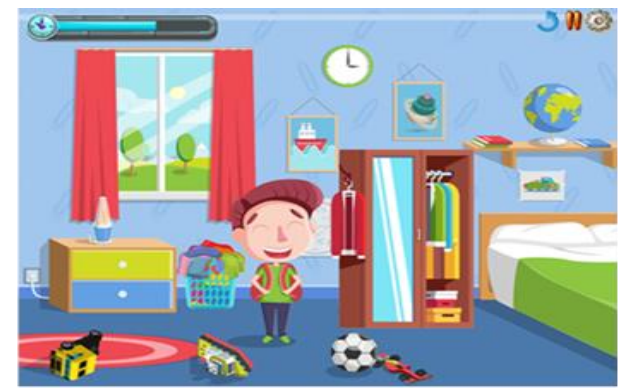

Fig. 6. Game scene $\mathrm{S} \alpha$ (Bedroom)

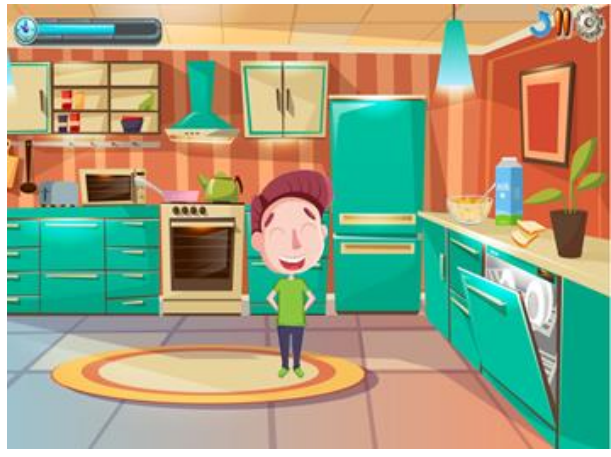

Fig. 7. Game scene $S \beta$ (Kitchen)

Following the child's decisions through the scenes, a semantic sub-network (see Fig. 8 and Fig. 9) of the child is generated as well as the child's matrice (see Fig. 10). It includes the concepts and actions made by the child. And by applying the formula (*), we obtain the new weights of the concepts compared to the main concept. Table 6 illustrates the new concept's weights. 


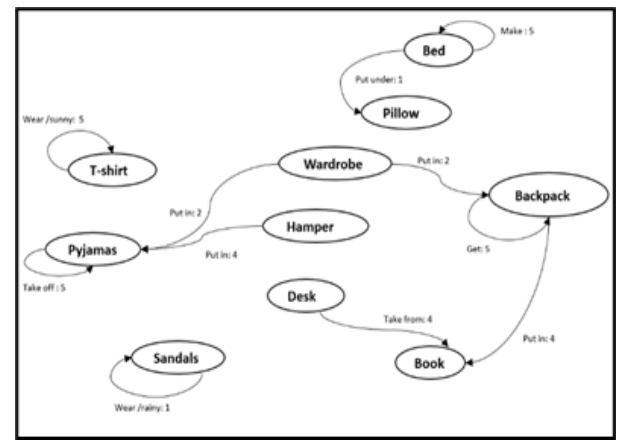

Fig. 8. Child's sub-semantic network $\mathrm{S} \alpha$

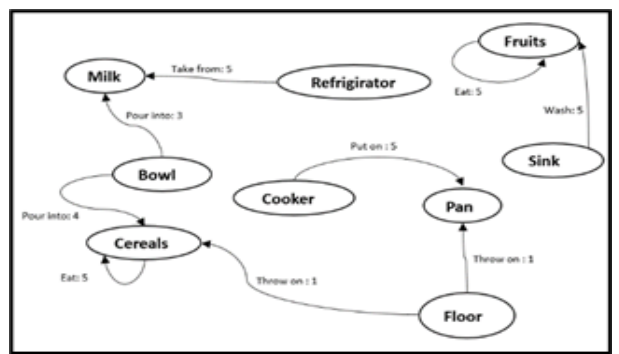

Fig. 9. Child's sub-semantic network $S \beta$

\begin{tabular}{|c|c|c|c|c|c|c|c|}
\hline scene $_{\alpha}$ & 童 & $\frac{1}{8}$ & 童 & 善 & $\mathbb{Z}$ & $\frac{\bar{z}}{\frac{b}{2}}$ & $\frac{\mathrm{u}}{\mathrm{z}}$ \\
\hline Wear/amary & 5 & 0 & 0 & 0 & 0 & 0 & 0 \\
\hline Tusc off & 0 & 5 & 0 & 0 & 0 & 0 & 0 \\
\hline Pat in wartidode & 0 & 2 & 0 & 0 & 0 & 0 & 0 \\
\hline Pat in hamper & 0 & ${ }_{4}$ & 0 & 0 & 0 & 0 & 0 \\
\hline Mate & 0 & 0 & 0 & 0 & 5 & 0 & 0 \\
\hline Pru under Bed & 0 & 0 & 0 & 0 & 0 & 1 & 0 \\
\hline Wear / riainy & 0 & 0 & 1 & 0 & 0 & 0 & 0 \\
\hline 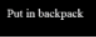 & 0 & 0 & 0 & 4 & 0 & 0 & 0 \\
\hline Take from deak & 0 & 0 & 0 & 4 & 0 & 0 & 0 \\
\hline cot & 0 & 0 & 0 & 0 & 0 & 0 & 5 \\
\hline Put in watloble & 0 & 0 & 0 & 0 & 0 & 0 & 2 \\
\hline
\end{tabular}

\begin{tabular}{|c|c|c|c|c|}
\hline Scene $_{\beta}$ & 竞 & ti & $\stackrel{\nexists g}{2}$ & \\
\hline Pour int boul & 3 & 0 & 0 & \\
\hline Tale fruen refigitirater & 5 & 0 & 0 & \\
\hline Eat & 0 & 0 & 0 & \\
\hline Pour into boul & 0 & 4 & 0 & \\
\hline Wash in inink & 0 & 0 & 0 & \\
\hline Put on coster & 0 & 0 & s & \\
\hline Therow on floor & 0 & 0 & 1 & \\
\hline Therow a f floor & 0 & 1 & 。 & \\
\hline Eat & 0 & 5 & 。 & \\
\hline
\end{tabular}

Fig. 10. Child's matrice 
Table 6. Child's weights of concepts

\begin{tabular}{|c|c|c|c|c|c|c|c|c|c|c|c|}
\hline Scene & \multicolumn{7}{|c|}{ Scene $: S_{\alpha}$} & \multicolumn{4}{|c|}{ Scene $: S_{\beta}$} \\
\hline 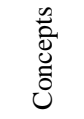 & $\begin{array}{l}\text { : } \\
\text { 辛 } \\
\stackrel{1}{H}\end{array}$ & 䓵 & 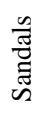 & $\begin{array}{l}\frac{4}{0} \\
0\end{array}$ & 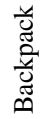 & $\ddot{D}$ & 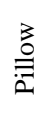 & 总 & 总 & च & 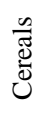 \\
\hline 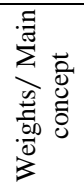 & 4 & 3 & 3 & 5 & 5 & 2 & 1 & 3 & 4 & 4 & 5 \\
\hline
\end{tabular}

The goal is to measure if the child understands the concept "getting ready to school", this evaluation takes as parameter the vectors of the child and the expert including the weights of the concepts (see Table 5 and Table 6). We obtain by applying the cosine similarity technique, for the scene $\alpha$ (Bedroom) a value of angle separating the vectors of the child and the expert which is equal to: $\boldsymbol{\theta}=\mathbf{2 5}^{\circ}$ (see Fig. 13), whose cosine is equal to: $\cos \left(\boldsymbol{V}_{\text {child }}, \boldsymbol{V}_{\text {expert }}\right)=\mathbf{0 . 9}$. For the second scene $\beta$ which corresponds to the kitchen (see Fig. 14), the measure of similarity between the sub-concepts of the child and the expert is estimated to $42^{\circ}$.

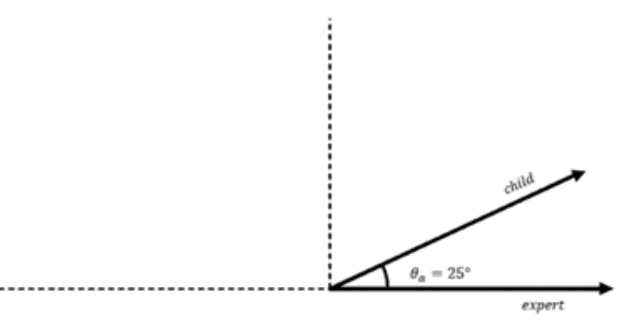

Fig. 11. Angle between expert and child concepts $\left(S_{\alpha}\right)$

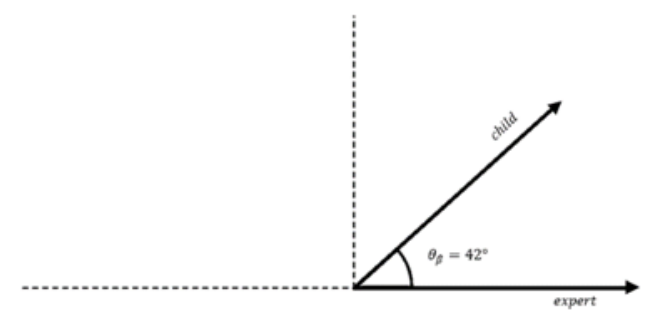

Fig. 12. Angle between expert and child concepts $\left(S_{\beta}\right)$

Besides, we notice that the child partially masters the concept "getting ready to school". Moreover, he understands the missions linked to the bedroom much better than 
those linked to the kitchen. Next, we determine the actions that caused a significant degradation in the concept's weights.

For the "Kitchen" scene, the actions are:

- Put pyjamas in wardrobe

- Put pillow under bed

- Wear sandals on a rainy day

- Put backpack in wardrobe

For the "Bedroom" scene, the actions are:

- Pour milk into bowl

- Throw cereals on floor

- Throw pan on floor

After identifying actions that have considerably influenced the weights of the concepts, we can clearly see that for example for the child has difficulty assimilating the notion of the weather, to choose the suitable shoes to wear when it rains. About, the child emitted the same action "throw on floor" twice which can be translated by an aggressive behavior which reflects a sign related to the ASD or it comes from another origin. The interpretation of the results of the technique provided by the expert requires the intervention of tutors and parents to ensure proper support for the child with ASD.

\section{Discussion}

Feedback and evaluation are inseparable from educational objectives and learning activities. The proposed technique aims to measure the degree of assimilation of a concept by a child with ASD at preschool age; it is an innovative and potentially powerful tool to assess this degree of assimilation through serious games. Indeed, the serious games sector is a promising area because it constitutes an excellent test bench, as well as a field of application, for evaluation. The technique offers several advantages such as:

- Allowing regular monitoring of the child's progress helps keep learning objectives in mind so the tutors can help dispel ambiguous concepts in the child.

- Take advantage of children's engagement in playful environments to tacitly assess their understanding on a given concept.

- Identify continuous improvement strategies.

Nevertheless, describing all the possible reactions of the child proves to be a difficult step for the expert because he must define all the reactions that can be carried out in the space of the game. However, the assessment for learning refers to more than just a form of assessment, rather it encompasses an approach to education and learning whereby the tutors and parents are constantly informed of the development of the child learning. 


\section{Conclusion}

Evaluation is used for a variety of purposes, one of the major goals is to foster learning. Evaluate in order to provide a precise and personalized learning assistance to the learner. As well as evaluating a child's activity, performance or progress is often a great way to improve and validate learning. In this article, we propose a technique for evaluating the degree of assimilation of an autistic child, it is carried out during learning and will help tutors to identify concepts not well assimilated by the child, to become aware what the child has already learned or what remains to be learned.

The proposed technique uses serious games as a tool to measure children's reactions in game scenes in a tacit manner. It will assess metacognitive control, in other words, how the child builds and uses his own knowledge.

\section{$7 \quad$ References}

[1] Diagnostic and statistical manual of mental disorders. Washington, D.C: American Psychiatric Association, 2013.

[2] S. Baron-Cohen, L. Cosmides, J. Tooby and J. Rosenschein, Mindblindness. Cambridge: MIT Press, 1995.

[3] L. Allal and D. Laveault, "Assessment for Learning", Mesure et évaluation en éducation, vol. 32, no. 2, p. 99, 2009. Available: https://doi.org/10.7202/1024956ar.

[4] P. Black and D. Wiliam, "Assessment and Classroom Learning", Assessment in Education: Principles, Policy \& Practice, vol. 5, no. 1, pp. 7-74, 1998. Available: https://doi.org/10.10 80/0969595980050102.

[5] The House of Commons, Testing and Assessment. London: Third Report of Session 200708, 2008.

[6] H. Roediger, P. Agarwal, M. McDaniel and K. McDermott, "Test-enhanced learning in the classroom: Long-term improvements from quizzing.", Journal of Experimental Psychology: Applied, vol. 17, no. 4, pp. 382-395, 2011. Available: https://doi.org/10.1037/a0026252.

[7] M. Musial and F. Pradere, Comment concevoir un enseignement ? Bruxelles: De Boeck, 2012.

[8] M. Mazurek and C. Engelhardt, "Video Game Use in Boys with Autism Spectrum Disorder, ADHD, or Typical Development", PEDIATRICS, vol. 132, no. 2, pp. 260-266, 2013. Available: https://doi.org/10.1542/peds.2012-3956

[9] C. Abt, Serious games. Lanham, MD: University Press of America, 1970.

[10] S. Egenfeldt-Nielsen, B. Meyer and B. Sørensen, Serious Games in Education. Santa Barbara: Aarhus University Press, 2011.

[11] F. Fröbel and J. Jarvis, Friedrich Froebel's Pedagogics of the Kindergarten: Or, His Ideas Concerning the Play and Playthings of the Child. New York: D. Appleton and Co., 1896.

[12] Z. de Urturi, A. Zorrilla and B. Zapirain, "A Serious Game for Android Devices to Help Educate Individuals with Autism on Basic First Aid", Advances in Intelligent and Soft Computing, pp. 609-616, 2012. Available: https://doi.org/10.1007/978-3-642-28765-7 74

[13] S. Bernardini, K. Porayska-Pomsta and T. Smith, "ECHOES: An intelligent serious game for fostering social communication in children with autism", Information Sciences, vol. 264, pp. 41-60, 2014. Available: https://doi.org/10.1016/j.ins.2013.10.027

[14] R. Amoroso, Serious Games: la nuova frontiera dell'apprendimento, In Bricks, pp. 17-22, 2012. 
[15] K. Matsushita, "An Invitation to Deep Active Learning", Deep Active Learning, pp. 15-33, 2017. Available: https://doi.org/10.1007/978-981-10-5660-4 2

[16] M. El Alami and F. de Arriaga, "Fuzzy Assessment for Affective and Cognitive Computing in Intelligent E-learning Systems", International Journal of Computer Applications, vol. 100, no. 10, pp. 40-46, 2014. Available: https://doi.org/10.5120/17564-8192.

[17] M. El Alami, M. Romero and F. de Arriaga, "NEW METHODS FOR STUDENT LEARNING ASSESSMENT", ICERI2011 Proceedings, Madrid, 2011.

[18] H. Roediger and J. Karpicke, "Test-Enhanced Learning", Psychological Science, vol. 17, no. 3, pp. 249-255, 2006. Available: https://doi.org/10.1111/j.1467-9280.2006.01693.x.

[19] S. Kim, V. Hus and C. Lord, "Autism Diagnostic Interview-Revised", Encyclopedia of Autism Spectrum Disorders, pp. 345-349, 2013. Available: https://doi.org/10.1007/978-14419-1698-3_894.

[20] C. Lord et al., Journal of Autism and Developmental Disorders, vol. 30, no. 3, pp. 205-223, 2000. Available: 10.1023/a:1005592401947.

[21] E. Schopler, Childhood autism rating scale. Los Angeles: Western Psychological Services, 2010.

[22] F. Glascoe, "Parents' Evaluation of Developmental Status: How Well Do Parents' Concerns Identify Children with Behavioral and Emotional Problems?", Clinical Pediatrics, vol. 42, no. 2, pp. 133-138, 2003. Available: https://doi.org/10.1177/000992280304200206.

[23] J. Gilliam, Gilliam Autism Rating Scale. Austin: Pro-Ed, 2014.

[24] STAT. Available: http://stat.vueinnovations.com/about

[25] L. Millar et al., "Phase 3 diagnostic evaluation of a smart tablet serious game to identify autism in 760 children 3-5 years old in Sweden and the United Kingdom", BMJ Open, vol. 97, 2019. Available: https://doi.org/10.1136/bmjopen-2018-026226.

[26] A. Alharbi, "Knowledge and Attitude of Families and Health Care Providers towards Autism", Open Access Journal of Public Health, vol. 2-2-14, 2018.

[27] S. Ellias and H. Shah, "A study of assessment of knowledge of childhood autism among medical students in Mumbai", Annals of Indian Academy of Neurology, vol. 0, no. 0, p. 0, 2019. Available: https://doi.org/10.4103/aian.aian_486_17

[28] Y. Liu et al., "Knowledge, attitudes, and perceptions of autism spectrum disorder in a stratified sampling of preschool teachers in China", BMC Psychiatry, vol. 16, no. 1, 2016. Available: $10.1186 / \mathrm{s} 12888-016-0845-2$.

[29] N. Tahiri and M. El Alami, "KASP: A Cognitive-Affective Methodology for Designing Serious Learning Games", International Journal of Advanced Computer Science and Applications, vol. 9, no. 11, 2018. Available: https://doi.org/10.14569/ijacsa.2018.0911103.

[30] M. El Alami, N. Tahiri and F. de Arriaga, "DIAUTIS: A Fuzzy and Affective Multi-agent Platform for the Diagnosis of Autism", British Journal of Applied Science \& Technology, vol. 21, no. 4, pp. 1-28, 2017. Available: https://doi.org/10.9734/bjast/2017/33716.

[31] R. Likert, A Technique for the measurement of attitudes. New York, 1932.

\section{Authors}

Najoua Tahiri is a Ph.D. Candidate at the mathematics, computer science and applications research team (ERMIA), National School of Applied Sciences of Tangier, Abdelmalek Essaâdi University, Tétouan, Morocco. Engineer degree in Computer Science in 2013. Ongoing research interests: Knowledge-Based System, Artificial Intelligence, Affective Computing, E-learning. 
Mohamed El Alami is Qualified Professor at National School of Applied Sciences of Tangier. Ph.D in Computer Science in 1998 from Faculty of Computer Science, Polytechnic University of Madrid. Member of the mathematics, computer science and applications research team (ERMIA). Author of several research publications. Ongoing research interests: Knowledge-Based System, Artificial Intelligence, Affective Computing, Cognitive neuroscience, Intelligent Learning System.

Article submitted 2019-12-20. Resubmitted 2020-02-18. Final acceptance 2020-02-21. Final version published as submitted by the authors. 